\section{BRITISH RAINFALL IN I9II.}

THE Director of the British Rainfall Organisation is to be congratulated on the volume he has produced ${ }^{1}$ dealing with the rainfall of the British Isles, and for the compilation of which he has the assistance of 5300 observers. As time goes on the value of the work undertaken is greatly enhanced, not only by the extension of the observations and the greater accuracy of the results, but also by the completeness of the discussions rendered possible by the accumulation of data. The thoroughness with which the work is carried out both by the voluntary observers and by Dr. Mill and his assistants merits the greatest

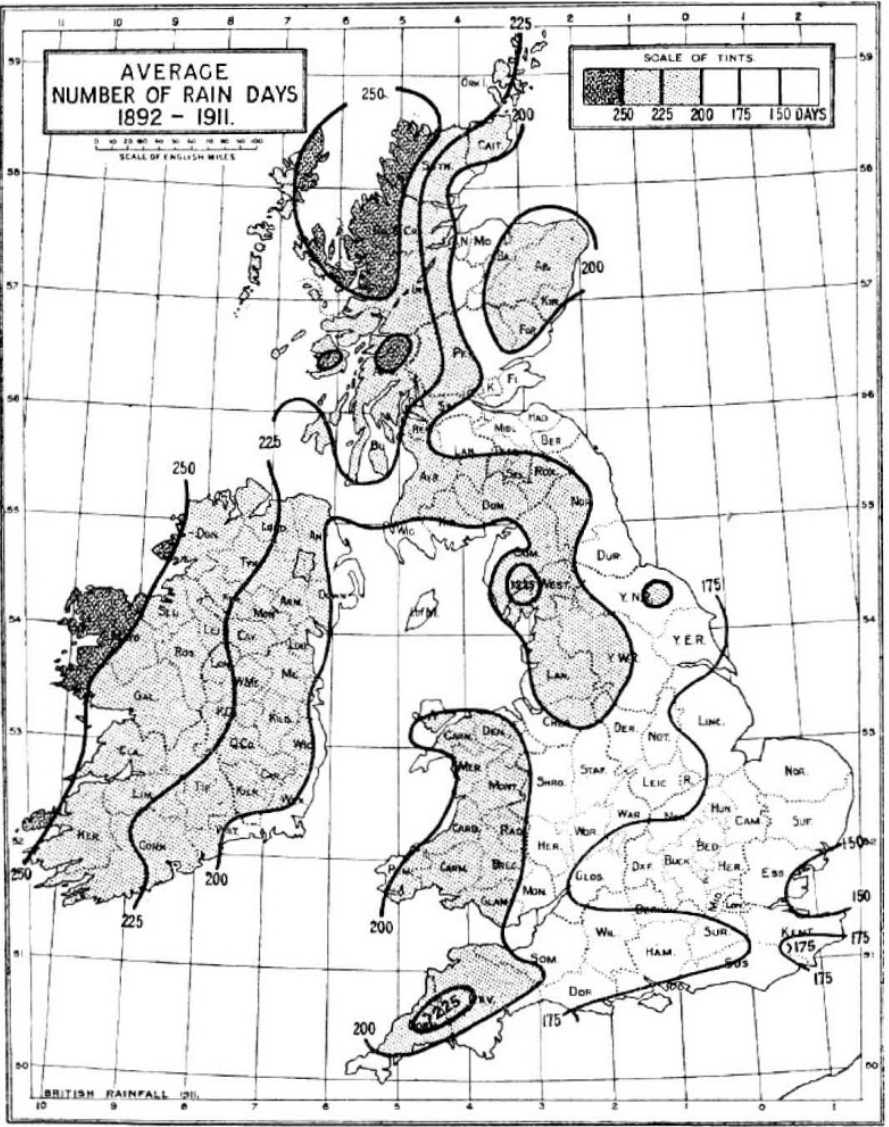

embracing chiefly a dry period. Now a period of twenty years, I892 to I $19 \mathrm{I}$, is dealt with, and the results at roo stations of established accuracy have been collated, which may with some confidence be expected to furnish a trustworthy average.

There is naturally a relation existing between the frequency and amount of rainfall, the wetter western districts showing a greater frequency than the relatively drier Eastern districts.

The rain days for the year on the average of twenty years range from 250 in the north-west of Scotland and the west of Ireland to 150 in the estuary of the Thames; and England, with the exception of the north-western and western districts, has fewer than 200 rain days in the year.

The map of frequency, like that of quantity, suggests very clearly the controlling influence of the westerly winds which predominate, and which are laden with moisture from off the Atlantic on their arrival over the British Isles.

The abnormal year of I9ri was believed to have been unparalleled for its dry periods, and under the heading of "Droughts in rgII" a comparison is made between the results for IgrI and the records of the last twenty-four years, selecting one hundred well-distributed stations in the British Isles; this shows that the surmise about I9r I is not without foundation. Igrr had more absolute droughts than any other year except I887, and it had the largest number of partial droughts. An absolute drought is no rain for more than fourteen consecutive days, and a partial drought a period of more than twenty-eight consecutive days with a mean rainfall not exceeding $0^{\circ}$ or in. per day. The absolute droughts in I9I I were more than double the average, and partial droughts little short of three times the average.

Dealing with heavy rains in short periods, an exceedingly interesting table is given showing the rainfalls of very rare intensity lasting for one hour or less. The heaviest authenticated measurement is $0^{\circ} 33$ in. in two minutes, which is equal to the hourly rate of 9.90 in. at Chepstow in March, 1888, and this is followed

admiration, and is a masterpiece as a private undertaking.

A discussion of the distribution of rainfall in time is given which will prove of very great value, and is a matter of considerable interest even to the general public endowed merely with average scientific craving.

In a former volume for 1902, a first attempt was made in the same direction, dealing only with the observations for ten years, and these

1 "British Rainfall, rgrr." On the Distribution of Rain in Space and Time over the British Jsles during the Year 1911 , as recorded by more than 5000 Observers in Great Britain and lreland, and discussed with Articles upon various branches of Rainfall Work. By Dr. H. R. Mill. The Fiftyfirst Annual Volume. Pp. ro $8+388$. (London: Edward Stanford, Ltd., 19r2.) frice ros.

NO. 2242 , VOL. 907 by 0.50 in. in four minutes, which is equivalent to $7^{\circ} 5^{\circ}$ in. per hour, at Ilkley in June, 1906. A reported fall of $\mathrm{r}_{25}$ in. in five minutes at Preston in August, 1893 , which gives a rate of ${ }^{5} 5$ in. per hour, is accepted with caution. At Beddington, in May, 1903, a fall of 3.50 in. occurred in an hour. This table is of considerable value, as it affords means of comparison for such extraordinary rains as have recently occurred in Norfolk, where at Norwich, between noon and I p.m., September 26 , the rainfall amounted to $x^{\circ} \times 5$ in., and to $7 \cdot 32$ in. in twenty-four hours ending 4 a.m:, September 27.

C. $\mathrm{H}$. 